\title{
Progress in Clinical Neurosciences: Pharmacotherapies for the Secondary Prevention of Stroke
}

\author{
Daniel G. Hackam and Moira K. Kapral
}

\begin{abstract}
Stroke is a leading cause of mortality and long-term disability worldwide. Survivors of a previous stroke or transient ischemic attack are vulnerable to further cerebrovascular events, as well as myocardial infarction, peripheral vascular disease, congestive heart failure and vascular death. Traditional approaches to the secondary prevention of stroke have included aspirin after ischemic stroke, warfarin for stroke associated with cardioembolic sources, and carotid endarterectomy for eligible candidates with significant carotid artery stenosis. In recent years, much evidence has emerged to support a broader array of pharmacotherapies, including newer antiplatelet agents, lipid lowering drugs, and several classes of blood pressure lowering therapies. Also under study are B vitamins for patients with cerebrovascular disease and hyper-homocysteinemia, and oral direct thrombin inhibitors for highrisk patients with atrial fibrillation. We review the literature to determine the clinical significance of these therapies, and provide recommendations regarding their use in the prevention of recurrent stroke.
\end{abstract}

RÉSUMÉ: Revue de la pharmacothérapie en prévention secondaire de l'accident vasculaire cérébral. L'accident vasculaire cérébral (AVC) est une cause importante de mortalité et d'invalidité à long terme dans le monde entier. Les patients qui survivent à un $\mathrm{AVC}$ ou à un épisode transitoire d'ischémie cérébrale sont sujets à d'autres événements vasculaires cérébraux ainsi qu'à l'infarctus du myocarde, à la maladie vasculaire périphérique, à l'insuffisance cardiaque et à la mort vasculaire. Les approches traditionnelles en prévention secondaire de l'AVC sont l'aspirine après un AVC ischémique, la warfarine après un AVC embolique d'origine cardiaque et l'endartérectomie carotidienne chez les patients présentant une sténose carotidienne importante. Depuis quelques années, des observations en faveur de l'utilisation d'une pharmacothérapie plus diversifiée, incluant de nouveaux antiplaquettaires, des hypolipidémiants et plusieurs classes d'agents antihypertenseurs, ont été rapportées dans la littérature. Les vitamines du complexe B chez les patients atteints de maladie cérébrovasculaire accompagnée d'hyperhomocystéinémie et les inhibiteurs oraux directs de la thrombine chez les patients à haut risque à cause d'une fibrillation auriculaire sont également à l'étude. Nous revoyons la littérature afin de déterminer quelle est la place de ces médicaments en clinique et d'élaborer des recommandations sur leur utilisation pour prévenir un nouvel AVC.

Can. J. Neurol. Sci. 2004; 31: 295-303

Stroke is the leading cause of neurological disability and the second leading cause of mortality worldwide. ${ }^{1}$ In 2001, it was estimated that 5,454,000 fatal cerebrovascular events occurred globally. The burden of disease, represented in years of healthy life lost was also enormous: 45,870,000 disability-adjusted life years were due directly to cerebrovascular disease in $2001{ }^{1}$ Current projections indicate a $52 \%$ increase in cerebrovascular mortality by the year 2020, with over two thirds of cases occurring in the developing world. ${ }^{2}$

Patients who survive a stroke or transient ischemic attack (TIA) are especially vulnerable to recurrent cerebrovascular events. The long-term stroke recurrence rate ranges from four to $12 \%$ annually, with a particularly heightened risk in the first six months after an event. ${ }^{3-5}$ These secondary events contribute to the burden of illness in patients with cerebrovascular disease, increase physical and cognitive disability, and promote vascular dementia. ${ }^{6}$ Patients with a history of stroke or TIAare also more likely to suffer other forms of cardiovascular disease, including coronary artery disease, congestive heart failure, atrial fibrillation, and peripheral vascular disease. These conditions

From the Division of Clinical Pharmacology (DGH), Department of Medicine (MKK), University of Toronto, Institute for Clinical Evaluative Sciences, Toronto; Sunnybrook \& Women's College Hospital (DGH), and Division of General Internal Medicine and Clinical Epidemiology, University Health Network (MKK), Toronto, Ontario, Canada

ReCeived November 21, 2003. Acceptedin finalform February 5, 2004. Reprint requests to: Daniel G. Hackam, Suite 104, 50 Holly Street, Toronto, ON, Canada M4S 3E9 
predispose to a high long-term mortality after stroke, approximately $50-60 \%$ at five years. ${ }^{7}$

An extensive, burgeoning literature exists on secondary prevention measures for stroke. ${ }^{8}$ Traditional and well-validated approaches include aspirin after ischemic stroke or TIA, warfarin for patients with atrial fibrillation or other cardioembolic sources of stroke, and carotid endarterectomy for patients with symptomatic, high-grade carotid artery stenosis. ${ }^{9-11}$ In recent years, a number of additional pharmacological strategies have undergone evaluation, including newer antiplatelet agents, lipid lowering therapies, and blood pressure lowering agents. Also under study include oral direct thrombin inhibitors for high-risk patients with atrial fibrillation and B vitamins for patients with cerebrovascular disease and hyper-homocysteinemia. ${ }^{12} \mathrm{We}$ review the evidence pertaining to these approaches and formulate recommendations regarding their use in patients with a history of stroke or TIA.

\section{MethodS}

We conducted a systematic search of MEDLINE (years 19902003), the Cochrane Database, American College of Physicians Journal Club, and recent cardiovascular, neurological, and strokerelated symposiums for articles and abstracts on the epidemiology, prevention and treatment of cerebrovascular disease. We obtained further references by contacting experts in the field of stroke prevention, from review of personal files, and by hand-searching bibliographies of retrieved articles. Emphasis was placed on randomized controlled trials and systematic overviews, but observational and basic science studies were also considered.

Because atherosclerosis (the most common disease predisposing to stroke or TIA) is a systemic condition, and because patients with peripheral vascular or coronary artery disease are at greater risk of suffering stroke (as well as other cardiovascular events), we also considered interventions and trial information in these patient populations. Importantly, such literature usually includes stroke as an important outcome.

\section{ANTIPLATELET THERAPY}

Aspirin is the most frequently prescribed antiplatelet agent for secondary prevention in patients with a history of ischemic stroke or TIA, as well as for other high-risk vascular patients. ${ }^{13}$ Aspirin reduces platelet aggregation by inhibiting the production of thromboxane by the cyclo-oxygenase enzyme present in platelets; thromboxane is a potent mediator of platelet activation. A recently updated systematic overview by the Antithrombotic Trialists' Collaboration found that aspirin in patients with a history of vascular disease reduces the odds of a serious vascular event (stroke, myocardial infarction, or vascular death) by $22 \%$ (95\% confidence interval [CI] 15 to $29 \%$ ), and the odds of stroke alone by $30 \%$ (95\% CI $24 \%$ to $35 \%){ }^{9}$

Although aspirin is widely recommended as secondary prophylaxis following cerebral infarction, the residual risk of vascular events despite treatment with aspirin remains high: $12.9 \%$ of patients allocated to aspirin in the aforementioned overview still suffered a serious vascular event during a mean follow-up of 15 months. ${ }^{9}$ The phenomenon of aspirin resistance is well-documented in the cerebrovascular and coronary artery disease literature. ${ }^{14-16}$ Approximately $30-40 \%$ of patients with recurrent cerebrovascular events while on aspirin therapy are found to be aspirin-resistant by quantitative tests of platelet aggregation. ${ }^{15}$ Therefore, a number of alternative antiplatelet agents with different mechanisms of action have been pursued; the best-studied include dipyridamole (alone or in combination with aspirin) and the thienopyridine derivatives (ticlopidine and clopidogrel). ${ }^{9}$

A recent systematic review of 26 randomised controlled trials of dipyridamole for the secondary prevention of stroke studied three antiplatelet strategies: dipyridamole alone versus control (either placebo or another antiplatelet), combination dipyridamole plus aspirin versus aspirin alone, and combination diypridamole plus aspirin versus placebo. ${ }^{17}$ Dipyridamole monotherapy had no clear effect on the risk of vascular death (relative risk [RR] 1.02, 95\% CI 0.90-1.17), but did reduce the risk of nonfatal vascular events by $10 \%$ (95\% CI 2-17\%), an effect which only became statistically significant after the inclusion of a single large trial comprising 6,602 patients. $^{18}$ Dipyridamole plus aspirin versus aspirin alone again showed no clear difference in vascular death, and was associated with a marginal reduction in nonfatal vascular events (RR 0.90, 95\% CI 0.80-1.00). Combination dipyridamole and aspirin compared with placebo had a RR of 0.89 for vascular death (95\% CI 0.79 to 1.01 ), and a more robust RR of 0.74 for nonfatal vascular events (95\% CI 0.68 to 0.80). The ongoing European/Australian Stroke Prevention in Reversible Ischemia Trial, which is randomizing patients with cerebrovascular disease to one of three regimens (aspirin, combination aspirin/dipyridamole, or dose-adjusted warfarin), should provide further information on the possible benefits of aspirin/dipyridamole over aspirin alone. ${ }^{19}$ A second trial, the Prevention Regimen For Effectively Avoiding Second Strokes study, has recently begun enrollment and will compare combination aspirin/dipyridamole with aspirin/clopidogrel for the prevention of recurrent stroke. ${ }^{20}$

Hankey et $\mathrm{al}^{21}$ recently conducted a meta-analysis of trials comparing a thienopyridine (ticlopidine or clopidogrel) with aspirin for the secondary prevention of vascular disease. The thienopyridines exert their antiplatelet effect by blocking the adenosine-diphosphate receptor on the platelet surface, thereby inhibiting adenosine-mediated platelet activation. Overall, there was a modest, but statistically significant reduction in the odds of a serious vascular event in patients treated with a thienopyridine (odds ratio (OR) $0.91,95 \%$ CI: 0.84 to 0.98 ), corresponding to an absolute benefit of 11 serious vascular events per 1000 patients treated for two years. The odds of stroke were similarly reduced (OR $0.88,95 \%$ CI: 0.79 to 0.98 ), giving an absolute benefit of seven strokes avoided per 1000 patients treated for two years. The subset of patients with an inclusion history of cerebrovascular disease had a similar reduction in stroke (OR 0.86, 95\% CI: 0.75 to 0.97 ), but gained a larger absolute benefit (due to a higher risk of recurrent stroke): 16 strokes avoided per 1000 patients treated for two years. ${ }^{21}$

The same analysis found a decreased risk of gastrointestinal hemorrhage and upper gastrointestinal upset for thienopyridines compared with aspirin, but an increased risk of skin rash and diarrhea. ${ }^{21}$ Ticlopidine (but not clopidogrel) was associated with a significant increase in the odds of neutropenia and thrombotic thrombocytopenic purpura. Concerns about myelosuppression have largely led to the abandonment of ticlopidine in clinical 
practice. ${ }^{22}$ Another issue with the thienopyridines is their significantly greater expense than aspirin. A recent costeffectiveness analysis examined the use of clopidogrel for secondary prevention in patients with cerebrovascular disease. ${ }^{23}$ The authors calculated a net cost of $\$ 74,400$ (AUS\$; approximately $\$ 52,250$ USD) to prevent one stroke per year if clopidogrel was administered to all eligible patients with ischemic stroke or TIA instead of aspirin. Cost-benefit analysis for dual therapy with clopidogrel/aspirin for secondary prevention in patients who sustain cerebrovascular events on standard monotherapy has not been published, likely because randomized trials in this area are still ongoing. A widely available, standardized, and reliable test of platelet resistance to aspirin would likely considerably improve the cost-effectiveness of clopidogrel; however, this hypothesis has not yet been studied in trials of antiplatelet agents for secondary prevention.

\section{AnTiCOAgUlant THERAPY}

Oral anticoagulants, such as warfarin, have been tested for the prevention of both cardioembolic and noncardioembolic stroke. Patients with atrial fibrillation and previous cerebrovascular events are at considerable risk of recurrent stroke (approximately $12 \%$ per year); therapeutic anticoagulation with warfarin reduces this risk by approximately $62 \%$, with an $85 \%$ reduction in cardioembolic strokes. ${ }^{10}$ Two recently completed systematic reviews, however, found that anticoagulant therapy (of any intensity) was no more effective than antiplatelet therapy in the prevention of stroke (or other serious vascular events) in patients with a history of noncardioembolic (ie, arterial origin) stroke or TIA; not unexpectedly, oral anticoagulants were associated with a higher risk of serious hemorrhagic complications. ${ }^{24,25}$ The combination of warfarin and aspirin has been studied primarily in patients with coronary artery disease; some evidence of an incremental effect over monotherapy (i.e., warfarin or aspirin alone) has been reported, although it is unclear whether this benefit can be extrapolated to patients with cerebrovascular disease. ${ }^{26}$

Despite its proven efficacy for stroke prevention in patients with atrial fibrillation, warfarin continues to be substantially underused in this population. ${ }^{27}$ For many years, the only alternative to warfarin in atrial fibrillation was antiplatelet therapy with aspirin, which provides only a modest reduction in the risk of cardioembolic events. ${ }^{28}$ However, a novel class of anticoagulant drugs, the direct thrombin inhibitors, are currently in development for the prevention and treatment of both arterial and venous thromboembolism; one agent in this class, ximelagatran, appears particularly promising. ${ }^{29}$ Its advantages over warfarin include excellent oral bioavailability, rapid onset of action, no requirement for dose adjustment or coagulation monitoring, and no interactions reported to date with other drugs or diet. ${ }^{29}$

Recently, the results of a large, open-label phase III noninferiority study of ximelagatran versus warfarin in high-risk patients with atrial fibrillation were presented. ${ }^{30}$ Altogether, 3407 patients with atrial fibrillation and additional stroke risk factors (eg, a quarter had previous stroke or TIA, and a third had coronary artery disease), were randomized to treatment with fixed-dose, unmonitored ximelagatran or standard, dose-adjusted warfarin (international normalized ratio (INR) 2.0-3.0). Despite assiduous anticoagulation in the warfarin arm (the mean INR on treatment was 2.5), the ximelagatran group had a significant reduction in the combined endpoint of stroke, major bleeding, and death (relative risk reduction (RRR) 25\%, $\mathrm{p}=0.022$ ). ${ }^{30}$ The presentation of another large, double-blind trial of ximelagatran in high-risk patients with atrial fibrillation has recently confirmed the noninferiority of ximelagatran with respect to warfarin in this setting. ${ }^{31}$ If these results are validated by other ongoing studies, ximelagatran could prevent thousands of strokes per year in patients with atrial fibrillation who are currently not treated with any anticoagulation.

\section{LIPID LOWERING THERAPY}

A number of statin trials, powered primarily to detect differences in coronary events rates in patients with a history of coronary artery disease, have found major reductions in the risk of stroke as well (a secondary outcome in these studies). ${ }^{32-36}$ Several systematic reviews of lipid-lowering therapies have affirmed the following points: 1) the relative reduction in stroke risk is on the order of $25-30 \%$; 2) ischemic stroke is reduced, with little effect on hemorrhagic stroke; and 3) the relative reduction in stroke events is constant irrespective of the baseline risk of stroke. ${ }^{37-40}$ The latter indicates that a greater absolute benefit may accrue from treating patients with a history of stroke or TIA, who have a markedly higher baseline risk of recurrent cerebrovascular events.

The possible mechanisms by which statins reduce the risk of ischemic stroke are multiple. Much attention has been paid to the "pleiotropic" or non-cholesterol related effects of statins on the vasculature and circulating blood elements. ${ }^{41}$ Human and experimental animal evidence demonstrate that statins stabilize atherosclerotic plaques, reduce vascular inflammation, improve blood flow to ischemic neural tissue, decrease free radical oxidative processes, inhibit platelet activation, and improve the balance between fibrinolysis and thrombosis. ${ }^{41}$ Many of these effects are apparent before a reduction in serum lipids takes place.

The recently completed Heart Protection Study (HPS) resolves many of the uncertainties regarding the role of statin therapy and secondary stroke prevention. ${ }^{42}$ The HPS randomized 20,536 patients to simvastatin or placebo for a mean duration of five years; inclusion criteria were any of the following: coronary artery disease, cerebrovascular disease, peripheral vascular disease, diabetes, or patients over 65 years with hypertension. There were highly significant reductions in the simvastatin arm in the incidence of major vascular events (absolute risk reduction (ARR) $5.4 \%$, number need to treat (NNT) 19), as well as cerebrovascular endpoints such as stroke, transient ischemic attack and the need for carotid endarterectomy or angioplasty. This benefit was evident in every subgroup tested: patients who had or did not have coronary artery disease; those with cerebrovascular disease, peripheral vascular disease, or diabetes; men or women; those over or under 75 years at entry; and those whose low density lipoprotein (LDL) cholesterol was over or under $2.6 \mathrm{mmol} / \mathrm{L}$. Indeed, treatment benefits were independent of the baseline cholesterol level, indicating that the LDL cholesterol thresholds currently recommended for initiation of 
treatment in high-risk patients may be too high. ${ }^{43,44}$ The results of HPS imply that the initiation of statin therapy should be based more on the assessment of a patient's absolute risk of cardiovascular disease, rather than just the baseline LDL cholesterol concentration. The ongoing Stroke Prevention by Aggressive Reduction in Cholesterol Levels (SPARCL) trial, which has randomized 4732 patients with cerebrovascular disease to atorvastatin $80 \mathrm{mg} /$ day or placebo, should provide further information on the merits of lipid-lowering for secondary prevention of stroke. ${ }^{45}$

A large meta-analysis of various lipid-lowering therapies (including statins, fibrates, niacin, bile acid sequestrants, and diet) found that only statins reduce the risk of stroke, with a risk reduction of $26 \%$ (95\% CI 14-36\%) for secondary prevention. ${ }^{37}$ Nonstatin drug therapy (with 32,550 subjects studied, of whom $73 \%$ were randomized in trials employing fibrates) was associated with a nonsignificant risk reduction of $7 \%$ (RR 0.93 ; 95\% CI $0.79-1.08$ ). Diet was employed as the primary modality in seven trials, involving 1741 participants; there was a trend towards stroke reduction in this subgroup (RR, 0.60; 95\% CI $0.32-1.13, \mathrm{p}=0.11$ ).

\section{BLOOD PRESSURE REDUCTION THERAPY}

Hypertension is estimated to account for about $60 \%$ of the population attributable risk for cerebrovascular disease. ${ }^{46-48}$ However, categorizing patients as "hypertensive" or "normotensive" based on an arbitrary blood pressure threshold may be unhelpful with respect to secondary stroke prevention for several reasons. First, the relationship between blood pressure and stroke is continuous and graded, with no evidence of a lower blood pressure threshold for stroke risk. ${ }^{49-51}$ Second, several controlled trials have demonstrated that blood pressure reduction benefits patients who would not normally be designated as hypertensive. ${ }^{52,53}$ Blood pressure lowering therapy reduces the risk of vascular events across a wide spectrum of initial blood pressures. $^{54}$ Furthermore, the choice of agent may be less important than the magnitude of blood pressure lowering achieved. ${ }^{55}$

Despite previous concerns that blood pressure lowering might cause harm in patients with cerebrovascular disease, the recently completed Perindopril Protection Against Recurrent Stroke Study (PROGRESS) demonstrates that aggressive blood pressure reduction provides substantial protection against recurrent vascular events in patients with previous stroke or TIA. ${ }^{53}$ The PROGRESS trial enrolled 6105 hypertensive and normotensive patients with a history of stroke or TIA, and randomly assigned them to active treatment with the angiotensin converting enzyme (ACE) inhibitor perindopril (with the discretionary addition of the diuretic indapamide), or matching placebo. ${ }^{53}$ Overall, perindopril-based therapy reduced the relative risk of stroke by $28 \%$ (95\% CI 17-38; ARR 4\%, NNT 25 ), with large reductions in the risk of myocardial infarction (RRR 38\%, 95\% CI 14-55), congestive heart failure (RRR 26\%, 95\% CI 5-42), and total major vascular events (ie, vascular death, myocardial infarction, or stroke; RRR 26\%, 95\% CI 1634). Analyses of cognitive outcomes indicate that the risk of poststroke dementia was reduced by a third and significant cognitive decline by a half. ${ }^{56}$ Of note, significant and similar reductions in stroke (and other vascular events) were apparent for both hypertensive and normotensive participants. ${ }^{53}$

Angiotensin receptor blockers have also demonstrated efficacy for the prevention of stroke in both the primary and secondary prevention settings. Three recently completed trials of angiotensin receptor blockers include the Losartan Intervention For Endpoint Reduction Study, the Acute Candesartan Cilexetil Therapy in Stroke Survivors Study (ACCESS), and the Study on Cognition and Prognosis in the Elderly. ${ }^{57-59}$ All three trials demonstrated consistent relative risk reductions for stroke in the range of 24 to $34 \%$, despite the enrolment of different patient populations, the use of varying angiotensin receptor blockers, and differing interventions in the control group (placebo-based or conventional therapy). Of particular interest, the ACCESS study showed that early initiation of candesartan cilexitil in the acute phase of stroke markedly reduced the risk of serious vascular events (both cardiac and cerebral), without compromising patient safety. ${ }^{59}$ Intriguingly, no blood pressure differences were noted between the treatment and placebo arms throughout the study, again raising the possibility that neurohumoral inhibition, rather than blood pressure lowering per se, may be responsible for the reduction in vascular risk.

Of the other therapies available to lower blood pressure, thiazide diuretics may also be particularly effective in secondary prevention. The Post-stroke Antihypertensive Treatment Study found that treatment with the diuretic indapamide reduced the risk of stroke by $29 \%$ in a group of hypertensive stroke or TIA survivors. ${ }^{60}$ Blood pressure was reduced by $5 / 2 \mathrm{~mm} \mathrm{Hg}$ (systolic/diastolic). This is highly consistent with a meta-analysis of blood pressure lowering trials in patients with cerebrovascular disease, which reported a $28 \%$ reduction in the risk of recurrent stroke (RR 0.72, 95\% CI 0.61 to 0.85 ). ${ }^{61}$

Two recent head-to-head studies of blood pressure lowering therapy found conflicting results for the comparison of thiazide diuretics and ACE inhibitors. ${ }^{62,63}$ In the Antihypertensive and Lipid-Lowering Treatment to Prevent Heart Attack Trial (ALLHAT), the diuretic chlorthalidone was significantly more effective than the ACE inhibitor lisinopril in the reduction of stroke, heart failure, angina, and combined cardiovascular disease. Conversely, in the Second Australian National Blood Pressure Study (ANBP-2), an ACE inhibitor was more effective than a diuretic in the prevention of cardiovascular events. The difference between the trials' results, while seemingly contradictory, is likely due to the much higher frequency of patients of African origin in the ALLHAT study (40\%) compared with the ANBP-2 study (<1\%). Low renin hypertension, which is more effectively targeted by diuretic therapy than ACE inhibitor therapy, is significantly more frequent in hypertensive patients of African origin. ${ }^{64,65}$ Therefore in black patients, diuretic therapy is a more logical first choice.

There is less evidence on the role of beta blockers and calcium channel blockers in the secondary prevention of stroke. A small trial of patients with previous TIA or nondisabling ischemic stroke who were randomized to atenolol or placebo reported a nonsignificant reduction in stroke of $18 \%$ in the atenolol arm, with a wide confidence interval (RR 0.82; 95\% CI 0.57-1.19). ${ }^{66}$ Moreover, the primary endpoint - a composite of vascular death, stroke, or myocardial infarction - was not affected by allocation to atenolol (RR 1.0; 95\% CI, 0.67-1.33), 
despite a significant reduction in blood pressure favouring the atenolol arm (5.8/2.9 $\mathrm{mm} \mathrm{Hg})$. On the other hand, a metaanalysis of beta blockers and diuretics for the treatment of hypertension in the elderly, a group that is particularly prone to stroke, found reductions in cerebrovascular events with both beta blockers and diuretics, although only the latter reduced the risk of fatal stroke, coronary artery disease, and all-cause mortality. ${ }^{67}$

To date, long-term, randomized trials of calcium channel blockers in patients with cerebrovascular disease have not been reported. These agents have shown particular promise in the primary prevention of stroke in patients with hypertension and/or diabetes. ${ }^{68,69}$ Furthermore, dihydropyridine calcium channel blockers appear to reduce the risk of dementia and cognitive decline in older hypertensive patients. ${ }^{70,71}$ Whether calcium channel blockers are effective in the secondary prevention of stroke will have to await the completion of trials enrolling highrisk patients (such as those with cerebrovascular disease); their outcomes are eagerly awaited. ${ }^{72,73}$ However, calcium channel blockers are not currently recommended as monotherapy for patients with vascular disease.

\section{OTHER THERAPIES}

Homocysteine is a highly reactive amino acid formed by demethylation of methionine. ${ }^{74}$ It is more appropriately termed "total homocysteine" (tHcy), as it represents a mixture of several molecular species and compounds. The metabolism of tHcy requires several B vitamins as substrates or cofactors, including folate, cobalamin (vitamin $\mathrm{B}_{12}$ ), and pyridoxine (vitamin $\mathrm{B}_{6}$ ). There is growing evidence that even mild elevations in plasma tHcy concentration predispose individuals to developing vascular disease, including stroke, carotid stenosis and dementia. ${ }^{75,76}$ Experimental studies have demonstrated a number of possible mechanisms by which tHcy may induce vascular damage, including the promotion of platelet activation, oxidative stress, endothelial dysfunction, hypercoagulability, vascular smooth muscle cell proliferation, and endoplasmic reticulum stress. ${ }^{74}$ The provision of oral B vitamin therapy to patients with hyper-homocysteinemia can effectively reduce plasma levels by $25-33 \% .^{77}$

Whether tHcy is truly causative in the pathogenesis of atherosclerosis (and therefore, a potentially treatable risk factor), or is merely a marker of existing vascular disease and tissue damage, will have to await the completion of several large controlled intervention studies on the effects of B vitamin therapy on cardiovascular endpoints. Two such trials in patients with cerebrovascular disease are ongoing: the Vitamin Intervention for Stroke Prevention trial and the Vitamins to Prevent Stroke Study. ${ }^{78,79}$ Completed trials in patients with coronary artery disease have yielded conflicting results. ${ }^{80-82}$

\section{DiscuSsion}

The nature and epidemiology of cerebrovascular disease renders the scourge of stroke highly amenable to prevention. First, as reviewed here, a variety of strategies have been validated based on sound clinical evidence stretching over thirty years (Table 1). ${ }^{83-85}$ Second, the burden of illness is substantial: at one year, one third of stroke patients are dead, another third are permanently disabled, and a final third will have made a reasonable recovery. ${ }^{86}$ Third, survivors of stroke or TIA are prone to recurrence as well as to disease in other vascular beds (heart, limbs, aorta, and viscera) and therefore represent an identifiable high-risk group for targeted intervention. ${ }^{6}$ Fourth, stroke is monumentally costly, not only physically and

Table 1: Benefits of pharmacological interventions for the prevention of stroke.

\begin{tabular}{|c|c|c|c|}
\hline $\begin{array}{l}\text { Drug class } \\
\text { Agent }\end{array}$ & \multicolumn{3}{|c|}{ Reduction in risk of stroke } \\
\hline \multicolumn{4}{|l|}{ Antiplatelet Agents } \\
\hline Clopidogrel $^{106 *}$ & $5.8 \%$ & $0.4 \%$ & 246 \\
\hline \multicolumn{4}{|l|}{ Antithrombotic Agents } \\
\hline Warfarin ${ }^{10} \dagger$ & $62 \%$ & $4.3 \%$ & 23 \\
\hline Statins $^{37}$ & $26 \%$ & $1.8 \%$ & 55 \\
\hline Nonstatin Therapies ${ }^{37}$ & NS & - & - \\
\hline \multicolumn{4}{|l|}{ Blood Pressure Lowering Agents } \\
\hline ACE Inhibitors ${ }^{93}$ & $30 \%$ & $2.1 \%$ & 48 \\
\hline Angiotensin Receptor Blockers ${ }^{69}$ & $24 \%$ & $1.7 \%$ & 60 \\
\hline Diuretics ${ }^{107}$ & $39 \%$ & $2.7 \%$ & 37 \\
\hline
\end{tabular}

\footnotetext{
Absolute risk reductions and numbers needed to treat per year are based on an average annual 7\% risk of stroke and the best available data from metaanalyses. ${ }^{23}$ Abbreviations: ACE=angiotensin-converting enzyme, ARR=absolute risk reduction, NNT=number needed to treat to prevent one event per year, NS=not significant, RRR=relative risk reduction. *clopidogrel versus aspirin. $\dagger$ in patients with atrial fibrillation. $\neq$ ximelagatran versus warfarin in patients with high-risk atrial fibrillation. §RRR for on-treatment analysis of strokes and systemic emboli.
} 
emotionally to patients and their families, but also financially to society and health care payers; therefore, many effective secondary prevention measures are likely to be cost-saving or cost-effective. ${ }^{23}$

Several paradigms are evident from a broad examination of the literature of stroke and vascular disease prevention. First, intensive treatment is more effective in reducing the risk of vascular events than moderate treatment. This is apparent for several stroke prevention strategies. For lipid-lowering therapies, more intensive cholesterol lowering yields greater risk reductions than modest cholesterol lowering: this is both apparent within studies and across studies. ${ }^{37,87-90}$ The same is true for blood pressure lowering; ample data support the concept that greater degrees of blood pressure reduction yield greater benefits in terms of coronary and stroke prevention. ${ }^{91-95}$ It may also be true for antiplatelet therapy; there is some evidence that dual platelet inhibition has additive effects on reducing vascular events (including stroke), although the case is considerably stronger in the coronary artery disease literature. ${ }^{17,96,97}$ A number of trials of dual platelet blockade for stroke prevention are ongoing; at this point, because of a relative paucity of data, combination antiplatelet therapy can not be recommended as initial therapy for patients with cerebrovascular disease.

Second, the clinical benefits of therapies reviewed here are not confined strictly to patients with elevated levels of a modifiable vascular risk factor (eg, high blood pressure or serum cholesterol). The reductions in risk in Heart Outcomes Prevention Evaluation study, PROGRESS, and HPS, for instance, were equally large and separately significant in individuals with average or even optimal levels of blood pressure and cholesterol. Such patients would normally not merit treatment under many existing clinical guidelines. ${ }^{98}$ Therefore, the concept of a " $\mathrm{J}$ curve" for reduction of cholesterol or blood pressure, in which there is a lower limit below which treatment increases event rates, is not supported by these trials. Indeed, blood pressure lowering therapy appears to be safe even in patients with carotid stenosis or occlusion. ${ }^{99}$

Third, the benefits of treatment with antiplatelet, lipidlowering, and blood pressure reduction therapies are present across all major patient subgroups: men and women, younger and older patients, those with or without diabetes, and individuals with different types of vascular disease or high-risk conditions. Moreover, unlike local revascularization procedures, these therapies reduce the risk of atherothrombotic events throughout the vascular tree, not just the cerebral circulation. For these reasons, the decision to implement drug therapy should be based on the absolute risk of vascular disease in a given individual, rather than the level of an individual risk factor, such as systolic blood pressure or LDL cholesterol. Survivors of stroke or TIA represent a particularly high-risk group of patients with vascular disease and, in the absence of contraindications, such patients stand to benefit substantially from preventive therapy with these agents. Since each strategy confers a $25-30 \%$ relative reduction in the risk of serious vascular events, the combination of all three strategies has the potential to yield an even greater risk reduction (about 60-70\%) than any therapy used alone. ${ }^{100}$ In addition, these therapeutic approaches should be used in combination with lifestyle changes, such as reduction in alcohol intake, smoking cessation, exercise, and dietary modification.
Table 2: Recommendations regarding drug therapies for secondary prevention in patients with a history of stroke or TIA.

\section{Antiplatelet Therapy}

Low dose aspirin $(75-150 \mathrm{mg} / \mathrm{d})$ for patients with ischemic stroke or TIA. Treatment should be started immediately in acute ischemic stroke, but should be delayed for 24 hours in patients receiving thrombolytic therapy.

If aspirin is not tolerated or allergy is present, reasonable alternatives include clopidogrel or dipyridamole.

\section{Anticoagulant Therapy}

Warfarin, adjusted to achieve a target INR of 2.5 , is preferred for patients with atrial fibrillation or other documented major cardioembolic sources (target INR 3.0 for mechanical heart valves).

\section{Anti-Lipid Therapy \\ Statins}

Most patients with ischemic stroke or TIA will benefit from statin therapy. Aggressive reduction of LDL cholesterol is likely to yield greater benefit than more modest reductions.

\section{Nonstatin Drug Therapy}

Some evidence suggests that nonstatin lipid lowering therapy may not be as effective as statins for secondary stroke prevention. ${ }^{37}$

\section{Blood Pressure Lowering Therapy}

Most patients with stroke or TIAwill benefit from treatment with a blood pressure lowering agent, regardless of the presence or absence of hypertension. For secondary prevention, ACE inhibitors, angiotensin receptor blockers, and thiazide diuretics have all been shown to reduce recurrent stroke and other vascular events. Beta blockers and calcium channel blockers may also be effective. Aggressive treatment of blood pressure is of greater benefit than more modest reductions.

$\mathrm{ACE}=$ angiotensin converting enzyme, INR=international normalized ratio, $\mathrm{LDL}=$ low density lipoprotein, TIA=transient ischemic attack.

Despite substantial evidence of effectiveness and safety, many of the interventions reviewed here continue to be underused in patients with established cerebrovascular disease. ${ }^{101}$ Only about $75 \%$ of eligible candidates with ischemic stroke are discharged on an antiplatelet or antithrombotic agent after the index admission. ${ }^{102}$ The use of statins in patients with stroke was under a third in several recent cohort studies. ${ }^{103,104}$ Control of hypertension after stroke or TIA is similarly poor. ${ }^{105}$ The reasons for undertreatment are multifactorial, and include patient, physician, and system-related factors. ${ }^{101}$ Whatever the cause, effective stroke prevention depends on application of available knowledge to high-risk patients, as well as the promotion of patient adherence to these therapies. The provision of these measures to all eligible, high-risk patients would prevent thousands of strokes and other serious vascular events each year.

The field of stroke prevention is a highly active area of research, and much more information is needed on the therapies reviewed herein. Direct thrombin inhibitors, B vitamins, and 
dual antiplatelet therapy can not yet be recommended for the secondary prevention of stroke; however, a number of ongoing intervention trials are studying these strategies. At this time, there is sufficient evidence to support several pharmacological strategies for patients with cerebrovascular events (who do not exhibit contraindications): 1) an antiplatelet or antithrombotic agent for patients with ischemic stroke or TIA; 2) a statin, irrespective of the presence or absence of hyperlipidemia or coronary artery disease; and 3) effective blood pressure lowering, possibly even in normotensive stroke survivors (Table 2). Accordingly, there is little room for therapeutic nihilism, and much reason to be optimistic, for patients who experience a stroke and the physicians who treat them.

\section{REFERENCES}

1. World Health Organization. The World Health Report 2002. Available at: http://www/who/int/whr/en/. Accessibility confirmed Jan 28, 2004.

2. Yusuf S, Reddy S, Ounpuu S, Anand S. Global burden of cardiovascular diseases: part I: general considerations, the epidemiologic transition, risk factors, and impact of urbanization. Circulation 2001; 104(22):2746-2753.

3. European Atrial Fibrillation Trial Study Group. Secondary prevention in nonrheumatic atrial fibrillation after transient ischaemic attack or minor stroke. Lancet 1993; 320;342(8882):1255-1262.

4. Hankey GJ, Jamrozik K, Broadhurst RJ, et al. Long-term risk of first recurrent stroke in the Perth Community Stroke Study. Stroke 1998; 29(12):2491-2500.

5. Wilterdink JL, Easton JD. Vascular event rates in patients with atherosclerotic cerebrovascular disease. Arch Neurol 1992; 49(8):857.

6. Wolf PA, Clagett GP, Easton JD, et al. Preventing ischemic stroke in patients with prior stroke and transient ischemic attack : a statement for healthcare professionals from the Stroke Council of the American Heart Association. Stroke 1999; 30(9):1991-1994.

7. Bravata DM, Ho SY, Brass LM, et al. Long-term mortality in cerebrovascular disease. Stroke 2003; 34(3):699-704.

8. Gorelick PB. Stroke prevention therapy beyond antithrombotics: unifying mechanisms in ischemic stroke pathogenesis and implications for therapy: an invited review. Stroke 2002; 33(3):862-875.

9. Antithrombotic Trialists' Collaboration. Collaborative metaanalysis of randomised trials of antiplatelet therapy for prevention of death, myocardial infarction, and stroke in high risk patients. Br Med J 2002; 324(7329):71-86.

10. Hart RG, Benavente O, McBride R, Pearce LA. Antithrombotic therapy to prevent stroke in patients with atrial fibrillation: a meta-analysis. Ann Intern Med 1999; 131(7):492-501.

11. Rothwell PM, Eliasziw M, Gutnikov SA, et al. Analysis of pooled data from the randomised controlled trials of endarterectomy for symptomatic carotid stenosis. Lancet 2003; 361(9352):107-116.

12. Olsson SB. Stroke prevention with the oral direct thrombin inhibitor ximelagatran compared with warfarin in patients with nonvalvular atrial fibrillation (SPORTIF III): randomised controlled trial. Lancet 2003; 362(9397):1691-1698.

13. Lalouschek W, Lang W, Mullner M. Current strategies of secondary prevention after a cerebrovascular event: the Vienna stroke registry. Stroke 2001; 32(12):2860-2866.

14. Eikelboom JW, Hirsh J, Weitz JI, et al. Aspirin-resistant thromboxane biosynthesis and the risk of myocardial infarction, stroke, or cardiovascular death in patients at high risk for cardiovascular events. Circulation 2002; 105(14):1650-1655.

15. Grundmann K, Jaschonek K, Kleine B, Dichgans J, Topka H. Aspirin nonresponder status in patients with recurrent cerebral ischemic attacks. J Neurol 2003; 250(1):63-66.

16. Gum PA, Kottke-Marchant K, Welsh PA, White J, Topol EJ. A prospective, blinded determination of the natural history of aspirin resistance among stable patients with cardiovascular disease. J Am Coll Cardiol 2003; 41(6):961-965.

17. De Schryver EL, Algra A, van Gijn J. Dipyridamole for preventing stroke and other vascular events in patients with vascular disease. Cochrane Database Syst Rev 2003;(1):CD001820.

18. Diener HC, Cunha L, Forbes C, et al. European Stroke Prevention Study. 2. Dipyridamole and acetylsalicylic acid in the secondary prevention of stroke. J Neurol Sci 1996; 143(1-2):1-13.

19. De Schryver EL. Design of ESPRIT: an international randomized trial for secondary prevention after nondisabling cerebral ischaemia of arterial origin. European/Australian Stroke Prevention in Reversible Ischaemia Trial (ESPRIT) group. Cerebrovasc Dis 2000; 10(2):147-150.

20. Prevention Regimen For Effectively avoiding Second Strokes. Available at: http://www.strokecenter.org/trials 2003.

21. Hankey G, Sudlow C, Dunbabin D. Thienopyridine derivatives (ticlopidine, clopidogrel) versus aspirin for preventing stroke and other serious vascular events in high vascular risk patients. Cochrane Database of Systematic Reviews 2003; 1, 2003.

22. Paradiso-Hardy FL, Angelo CM, Lanctot KL, Cohen EA. Hematologic dyscrasia associated with ticlopidine therapy: evidence for causality. Can Med Assoc J 2000; 163(11):1441-1448.

23. Hankey GJ, Warlow CP. Treatment and secondary prevention of stroke: evidence, costs, and effects on individuals and populations. Lancet 1999; 354(9188):1457-1463.

24. Sandercock P, Mielke O, Liu M, Counsell C. Anticoagulants for preventing recurrence following presumed noncardioembolic ischaemic stroke or transient ischaemic attack. Cochrane Database Syst Rev 2003;(1):CD000248.

25. Algra A, De Schryver EL, van Gijn J, Kappelle LJ, Koudstaal PJ. Oral anticoagulants versus antiplatelet therapy for preventing further vascular events after transient ischemic attack or minor stroke of presumed arterial origin. Stroke 2003; 34(1):234-235.

26. Hackam D, Anand SS, Yusuf S. Oral anticoagulant therapy in patients with coronary artery disease. Seminars in Vascular Medicine 2003; 3(3):323-332.

27. Cohen N, Almoznino-Sarafian D, Alon I, et al. Warfarin for stroke prevention still underused in atrial fibrillation: patterns of Omission. Stroke 2000; 31(6):1217-1222.

28. Connolly SJ. Preventing stroke in patients with atrial fibrillation: current treatments and new concepts. Am Heart J 2003; 145(3):418-423.

29. Hauptmann J. Pharmacokinetics of an emerging new class of anticoagulant/antithrombotic drugs. A review of small-molecule thrombin inhibitors. Eur J Clin Pharmacol 2002; 57(11):751-758.

30. Halperin JL. SPORTIF III: A Long-Term Randomized Trial Comparing Ximelagatran with Warfarin for Prevention of Stroke and Systemic Embolism in Patients with Nonvalvular Atrial Fibrillation. American College of Cardiology Annual Scientific Session. Late Breaking Clinical Trials III. Chicago, Illinois, USA. 4-1-2003.

31. Halperin JL. Efficacy and Safety Study of Oral Direct Thrombin Inhibitor Ximelagatran Compared with Dose-Adjusted Warfarin in the Prevention of Stroke and Systemic Embolic Events in Patients with Atrial Fibrillation (SPORTIF V). American Heart Association Scientific Sessions. Plenary Session VII: LateBreaking Clinical Trials. Orlando, Florida, USA. 2003.

32. Byington RP, Davis BR, Plehn JF, et al. Reduction of stroke events with pravastatin: the Prospective Pravastatin Pooling (PPP) Project. Circulation 2001; 103(3):387-392.

33. Scandinavian Simvastatin Survival Study Group. Randomised trial of cholesterol lowering in 4444 patients with coronary heart disease: the Scandinavian Simvastatin Survival Study (4S). Lancet 1994; 344(8934):1383-1389.

34. Plehn JF, Davis BR, Sacks FM, et al. Reduction of stroke incidence after myocardial infarction with pravastatin: the Cholesterol and Recurrent Events (CARE) study. The Care Investigators. Circulation 1999; 99(2):216-223.

35. Schwartz GG, Olsson AG, Ezekowitz MD, et al. Effects of atorvastatin on early recurrent ischemic events in acute coronary syndromes: the MIRACL study: a randomized controlled trial. JAMA2001; 285(13):1711-1718. 
36. White HD, Simes RJ, Anderson NE, et al. Pravastatin therapy and the risk of stroke. N Engl J Med 2000; 343(5):317-326.

37. Corvol JC, Bouzamondo A, Sirol M, et al. Differential effects of lipid-lowering therapies on stroke prevention: a meta-analysis of randomized trials. Arch Intern Med 2003; 163(6):669-676.

38. Crouse JR, III, Byington RP, Hoen HM, Furberg CD. Reductase inhibitor monotherapy and stroke prevention. Arch Intern Med 1997; 157(12): 1305-1310.

39. Ross SD, Allen IE, Connelly JE, et al. Clinical outcomes in statin treatment trials: a meta-analysis. Arch Intern Med 1999; 159(15):1793-1802.

40. Warshafsky S, Packard D, Marks SJ, et al. Efficacy of 3-hydroxy3-methylglutaryl coenzyme A reductase inhibitors for prevention of stroke. J Gen Intern Med 1999; 14(12):763-774.

41. Liao JK. Beyond lipid lowering: the role of statins in vascular protection. Int J Cardiol 2002; 86(1):5-18.

42. Heart Protection Study Collaborative Group. MRC/BHF Heart Protection Study of cholesterol lowering with simvastatin in 20,536 high-risk individuals: a randomised placebo-controlled trial. Lancet 2002; 360(9326):7-22.

43. Executive Summary of The Third Report of The National Cholesterol Education Program (NCEP) Expert Panel on Detection, Evaluation, And Treatment of High Blood Cholesterol In Adults (Adult Treatment Panel III). JAMA 2001; 285(19):2486-2497.

44. Wood D, De Backer G, Faergeman O, et al. Prevention of coronary heart disease in clinical practice. Summary of recommendations of the Second Joint Task Force of European and other Societies on Coronary Prevention. J Hypertens 1998; 16(10):1407-1414.

45. Amarenco P, Bogousslavsky J, Callahan AS, et al. Design and baseline characteristics of the stroke prevention by aggressive reduction in cholesterol levels (SPARCL) study. Cerebrovasc Dis 2003; 16(4):389-395.

46. Rodriguez BL, D'Agostino R, Abbott RD, et al. Risk of hospitalized stroke in men enrolled in the Honolulu Heart Program and the Framingham Study: a comparison of incidence and risk factor effects. Stroke 2002; 33(1):230-236.

47. Sacco RL, Wolf PA, Kannel WB, McNamara PM. Survival and recurrence following stroke. The Framingham study. Stroke 1982; 13(3):290-295.

48. Straus SEM, Majumdar SRM, McAlister FAM. New Evidence for Stroke Prevention: Scientific Review. JAMA 2002; 288(11):1388-1395.

49. Lewington S, Clarke R, Qizilbash N, Peto R, Collins R. Agespecific relevance of usual blood pressure to vascular mortality: a meta-analysis of individual data for one million adults in 61 prospective studies. Lancet 2002; 360(9349):1903-1913.

50. Rodgers A, MacMahon S, Gamble G, et al. Blood pressure and risk of stroke in patients with cerebrovascular disease. Br Med J 1996; 313(7050): 147.

51. MacMahon S, Peto R, Cutler J, et al. Blood pressure, stroke, and coronary heart disease. Part 1 . Prolonged differences in blood pressure: prospective observational studies corrected for the regression dilution bias. Lancet 1990; 335(8692):765-774.

52. Yusuf S, Sleight P, Pogue J, et al. Effects of an angiotensinconverting-enzyme inhibitor, ramipril, on cardiovascular events in high-risk patients. The Heart Outcomes Prevention Evaluation Study Investigators. N Engl J Med 2000; 342(3):145-153.

53. Progressive Collaborative Group. Randomised trial of a perindopril-based blood-pressure-lowering regimen among 6,105 individuals with previous stroke or transient ischaemic attack. Lancet 2001; 358(9287):1033-1041.

54. Sleight P, Yusuf S, Pogue J, et al. Blood-pressure reduction and cardiovascular risk in HOPE study. Lancet 2001; 358(9299):2130-2131.

55. Turnbull F. Effects of different blood-pressure-lowering regimens on major cardiovascular events: results of prospectively-designed overviews of randomised trials. Lancet 2003; 362(9395):1527-1535.

56. Tzourio C, Anderson C, Chapman N, et al. Effects of blood pressure lowering with perindopril and indapamide therapy on dementia and cognitive decline in patients with cerebrovascular disease. Arch Intern Med 2003; 163(9):1069-1075.
57. Dahlof B, Devereux RB, Kjeldsen SE, et al. Cardiovascular morbidity and mortality in the Losartan Intervention For Endpoint reduction in hypertension study (LIFE): a randomised trial against atenolol. Lancet 2002; 359(9311):995-1003.

58. Lithell H, Hansson L, Skoog I, et al. The Study on Cognition and Prognosis in the Elderly (SCOPE): principal results of a randomized double-blind intervention trial. J Hypertens 2003; 21(5):875-886.

59. Schrader J, Luders S, Kulschewski A, et al. The ACCESS Study: evaluation of Acute Candesartan Cilexetil Therapy in Stroke Survivors. Stroke 2003; 34(7):1699-1703.

60. PATS Collaborating Group. Post-stroke antihypertensive treatment study. A preliminary result. Chin Med J 1995; 108(9):710-717.

61. Gueyffier F, Boissel JP, Boutitie F, et al. Effect of antihypertensive treatment in patients having already suffered from stroke : gathering the evidence. Stroke 1997; 28(12):2557.

62. The ALLHAT Officers and Coordinators for the ALLHAT Collaborative Research Group. Major outcomes in high-risk hypertensive patients randomized to angiotensin-converting enzyme inhibitor or calcium channel blocker vs diuretic: the Antihypertensive and Lipid-Lowering Treatment to Prevent Heart Attack Trial (ALLHAT). JAMA2002; 288(23):2981-2997.

63. Wing LMH, Reid CM, Ryan P, et al. A Comparison of outcomes with angiotensin-converting-enzyme inhibitors and diuretics for hypertension in the elderly. N Engl J Med 2003; 348(7):583-592.

64. Baker EH, Duggal A, Dong Y, et al. Amiloride, a specific drug for hypertension in black people with T594M variant? Hypertension 2002; 40(1):13-17.

65. Spence JD. Physiologic tailoring of therapy for resistant hypertension: 20 years' experience with stimulated renin profiling. Am J Hypertens 1999; 12(11 Pt 1):1077-1083.

66. The Dutch TIA Trial Study Group. Trial of secondary prevention with atenolol after transient ischemic attack or nondisabling ischemic stroke. Stroke 1993; 24(4):543-548.

67. Messerli FH, Grossman E, Goldbourt U. Are \{beta\}-blockers efficacious as first-line therapy for hypertension in the elderly? A systematic review. JAMA1998; 279(23):1903-1907.

68. Effects of ACE inhibitors, calcium antagonists, and other bloodpressure-lowering drugs: results of prospectively designed overviews of randomised trials. Lancet 2000; 356(9246):19551964.

69. Staessen JA, Wang JG, Thijs L. Cardiovascular prevention and blood pressure reduction: a quantitative overview updated until 1 March 2003. J Hypertens 2003; 21(6):1055-1076.

70. Forette F, Seux ML, Staessen JA, et al. The prevention of dementia with antihypertensive treatment: new evidence from the Systolic Hypertension in Europe (Syst-Eur) study. Arch Intern Med 2002; 162(18):2046-2052.

71. Forette F, Seux ML, Staessen JA, et al. Prevention of dementia in randomised double-blind placebo-controlled Systolic Hypertension in Europe (Syst-Eur) trial. Lancet 1998; 352(9137):1347-1351.

72. Mann J, Julius S. The Valsartan Antihypertensive Long-term Use Evaluation (VALUE) trial of cardiovascular events in hypertension. Rationale and design. Blood Press 1998; 7(3):176183.

73. Sever PS, Dahlof B, Poulter NR, et al. Rationale, design, methods and baseline demography of participants of the AngloScandinavian Cardiac Outcomes Trial. ASCOT investigators. J Hypertens 2001; 19(6):1139-1147.

74. Mangoni AA, Jackson SH. Homocysteine and cardiovascular disease: current evidence and future prospects. Am J Med 2002; 112(7):556-565.

75. Wald DS, Law M, Morris JK. Homocysteine and cardiovascular disease: evidence on causality from a meta-analysis. Br Med J 2002; 325(7374):1202.

76. Hackam DG, Peterson JC, Spence JD. What level of plasma homocyst(e)ine should be treated? Effects of vitamin therapy on progression of carotid atherosclerosis in patients with homocyst(e)ine levels above and below 14 micromol/L. Am J Hypertens 2000; 13(1 Pt 1):105-110.

77. Homocysteine Lowering Trialists' Collaboration. Lowering blood 
homocysteine with folic acid-based supplements: meta-analysis of randomised trials. Indian Heart J 2000; 52(7 Suppl):S59-S64.

78. Spence JD, Howard VJ, Chambless LE, et al. Vitamin Intervention for Stroke Prevention (VISP) trial: rationale and design. Neuroepidemiology 2001; 20(1):16-25.

79. VITATOPS Trial Study Group. The VITATOPS (Vitamins to Prevent Stroke) Trial: rationale and design of an international, large, simple, randomised trial of homocysteine-lowering multivitamin therapy in patients with recent transient ischaemic attack or stroke. Cerebrovasc Dis 2002; 13(2):120-126.

80. Lange HW, Dambrink J-H, Pasalary M, et al. Folate Therapy Increases In-Stent Restenosis: Results From the Folate After Coronary Intervention Trial (FACIT). American College of Cardiology 52nd Annual Scientific Meeting March 30, 2003 Chicago, Illinois 2003.

81. Schnyder G, Roffi M, Flammer Y, Pin R, Hess OM. Effect of homocysteine-lowering therapy with folic acid, vitamin $\mathrm{B}(12)$, and vitamin $\mathrm{B}(6)$ on clinical outcome after percutaneous coronary intervention: the Swiss Heart study: a randomized controlled trial. JAMA2002; 288(8):973-979.

82. Liem A, Reynierse-Buitenwerf GH, Zwinderman AH, Jukema JW, van Veldhuisen DJ. Secondary prevention with folic acid: effects on clinical outcomes. J Am Coll Cardiol 2003; 41(12):2105-2113.

83. Acheson J, Danta G, Hutchinson EC. Controlled trial of dipyridamole in cerebral vascular disease. Br Med J 1969; 1(644):614-615.

84. Hypertension-Stroke Cooperative Study Group. Effect of antihypertensive treatment on stroke recurrence. JAMA 1974; 229(4):409-418.

85. Leren P. The Oslo diet-heart study. Eleven-year report. Circulation 1970; 42(5):935-942.

86. Hankey GJ. Stroke: How Large a Public Health Problem, and How Can the Neurologist Help? Arch Neurol 1999; 56(6):748.

87. Taylor AJ, Kent SM, Flaherty PJ, et al. ARBITER: Arterial Biology for the Investigation of the Treatment Effects of Reducing Cholesterol: a randomized trial comparing the effects of atorvastatin and pravastatin on carotid intima medial thickness. Circulation 2002; 106(16):2055-2060.

88. Knatterud GL, Rosenberg Y, Campeau L, et al. Long-term effects on clinical outcomes of aggressive lowering of low-density lipoprotein cholesterol levels and low-dose anticoagulation in the Post Coronary Artery Bypass Graft Trial. Circulation 2000; 102(2): 157.

89. Pitt B, Waters D, Brown WV, et al. Aggressive lipid-lowering therapy compared with angioplasty in stable coronary artery disease. Atorvastatin versus Revascularization Treatment Investigators. N Engl J Med 1999; 341(2):70-76.

90. Athyros VG, Papageorgiou AA, Mercouris BR, et al. Treatment with atorvastatin to the National Cholesterol Educational Program goal versus 'usual' care in secondary coronary heart disease prevention. The GREek Atorvastatin and Coronary-heartdisease Evaluation (GREACE) study. Curr Med Res Opin 2002; 18(4):220-228

91. Mehler PS, Coll JR, Estacio R, et al. Intensive blood pressure control reduces the risk of cardiovascular events in patients with peripheral arterial disease and type 2 diabetes. Circulation 2003; 107(5):753-756.
92. Progressive Collaborative Group. Randomised trial of a perindopril-based blood-pressure-lowering regimen among 6,105 individuals with previous stroke or transient ischaemic attack. Lancet 2001; 358(9287): 1033-1041.

93. Neal B, MacMahon S, Chapman N. Effects of ACE inhibitors, calcium antagonists, and other blood-pressure-lowering drugs: results of prospectively designed overviews of randomised trials. Blood Pressure Lowering Treatment Trialists' Collaboration. Lancet 2000; 356(9246): 1955-1964.

94. Hansson L, Zanchetti A, Carruthers SG, et al. Effects of intensive blood-pressure lowering and low-dose aspirin in patients with hypertension: principal results of the Hypertension Optimal Treatment (HOT) randomised trial. HOT Study Group. Lancet 1998; 351(9118):1755-1762.

95. Zanchetti A, Ruilope LM. Antihypertensive treatment in patients with type-2 diabetes mellitus: what guidance from recent controlled randomized trials? J Hypertens 2002; 20(11):20992110.

96. Steinhubl SR, Berger PB, Mann JT, III, et al. Early and sustained dual oral antiplatelet therapy following percutaneous coronary intervention: a randomized controlled trial. JAMA 2002; 288(19):2411-2420.

97. Yusuf S, Zhao F, Mehta SR, et al. Effects of clopidogrel in addition to aspirin in patients with acute coronary syndromes without STsegment elevation. N Engl J Med 2001; 345(7):494-502.

98. The sixth report of the Joint National Committee on prevention, detection, evaluation, and treatment of high blood pressure. Arch Intern Med 1997; 157(21):2413-2446.

99. Rothwell PM, Howard SC, Spence JD. Relationship between blood pressure and stroke risk in patients with symptomatic carotid occlusive disease. Stroke 2003; 34(11):2583-2590.

100 . Yusuf S. Two decades of progress in preventing vascular disease. Lancet 2002; 360(9326):2-3.

101. Holloway RGM, Benesch CM, Rush SRM. Stroke prevention: narrowing the evidence-practice gap. Neurology 2000; 54(10):1899-1906.

102. Hillen T, Dundas R, Lawrence E, et al. Antithrombotic and antihypertensive management 3 months after ischemic stroke : a prospective study in an inner city population. Stroke 2000; 31(2):469-475.

103. Tu JV, Gong Y. Trends in treatment and outcomes for acute stroke patients in Ontario, 1992-1998. Arch Intern Med 2003; 163(3):293-297.

104. Lalouschek W, Lang W, Greisenegger S, Mullner M. Determination of lipid profiles and use of statins in patients with ischemic stroke or transient ischemic attack. Stroke 2003; 34(1):105-110.

105. Kernan WN, Viscoli CM, Brass LM, et al. Blood pressure exceeding national guidelines among women after stroke. Stroke 2000; 31(2):415-419.

106. CAPRIE Steering Committee. A randomised, blinded, trial of clopidogrel versus aspirin in patients at risk of ischaemic events (CAPRIE). Lancet 1996; 348(9038):1329-1339.

107. Psaty BM, Lumley T, Furberg CD, et al. Health outcomes associated with various antihypertensive therapies used as firstline agents: a network meta-analysis. JAMA2003; 289(19):25342544. 